J. Reprod. Fert. (1971) 25, 243-252

\title{
STUDIES ON THE GROWTH AND ATRESIA OF GRAAFIAN FOLLICLES IN THE OVARY OF THE SHEEP*
}

\author{
T. C. SMEATON AND H. A. ROBERTSON \\ Animal Research Institute, Ottawa, Canada
}

\begin{abstract}
(Received 3rd Fuly 1970)
Summary. The growth and atresia of individual Graafian follicles in the ovaries of fourteen cycling Suffolk ewes were followed in vivo by marking the large follicle(s) present in the ovaries with Indian ink at three different times during the oestrous cycle. The ovaries containing marked follicles were removed on the 3rd to 9th day of the next cycle and sectioned to determine whether the follicles had ovulated. The results showed that follicles marked before the last day of the cycle regressed and did not ovulate. Only large follicles marked at, or just before, the onset of oestrus, ovulated and developed into corpora lutea. It is suggested that there are at least three phases of follicular growth and atresia during any one oestrous cycle which appear to be independent of circulating progesterone levels. Examination of sections of ovaries from a number of anoestrous and pregnant ewes gave no indication of a similar cyclic pattern of follicular growth and atresia.
\end{abstract}

\section{INTRODUCTION}

The growth of ovarian follicles during the oestrous cycle has been studied in several species of small mammals, including the rat (Boling, Blandau, Soderwall \& Young, 1941), the mouse (Peters \& Levy, 1966; Pedersen, 1970), and the guinea-pig (Myers, Young \& Dempsey, 1936), and in the large domestic animals, the pig (Robinson \& Nalbandov, 1951; Burger, 1952; Parlow, Anderson \& Melampy, 1964), the cow (Hammond, 1927; Cole, 1930; Rajakoski, 1960) and the sheep (Grant, 1934; McKenzie \& Terrill, 1937; Santolucito, Clegg \& Cole, 1960; Robertson \& Hutchinson, 1962; Hutchinson \& Robertson, 1966). In general, these investigations have shown that the follicle(s) destined to ovulate undergo rapid pre-ovulatory growth culminating in rupture at the time of ovulation (Cole, 1930; Grant, 1934; reviewed by Hisaw, 1947). However, the maturation and growth of follicles earlier in the oestrous cycle has received less attention and remains ill-defined for many species (Young, 1961 ; Everett, 1961).

In most of the studies cited above, the development of individual follicles has

* Contribution No. 386, Animal Research Institute. 
been deduced indirectly from observations on the number and size of the follicles present in the ovaries of animals killed at different stages of the oestrous cycle. Recently, however, Peters \& Levy (1966) and Pedersen (1970) used the uptake of $\left[{ }^{3} \mathrm{H}\right]$ thymidine by the follicles of the mouse ovary as an index of cell growth. They demonstrated that follicles of different sizes grew at different rates; small follicles tended to remain relatively inactive for long periods while large follicles increased rapidly in size and then either ovulated or regressed.

In the ewe, one, or more, follicles enlarge to a diameter of 4 to $5 \mathrm{~mm}$ during the first 4 to 5 days of the oestrous cycle (Robertson, 1969). Hutchinson \& Robertson (1966) have suggested that the follicle remains at this size until the onset of the next oestrus, unlike the cow in which there appear to be two successive waves of follicular growth during the oestrous cycle (Rajakoski, 1960). Other workers have proposed that follicular growth in the ewe continues steadily throughout the cycle (Grant, 1934; Kammlade, Welch, Nalbandov \& Norton, 1952).

The aim of the present experiments was to study follicular growth during the oestrous cycle of the ewe, and to determine whether the follicle which enlarges early in the cycle does in fact ovulate, as suggested previously (Dutt \& Casida, 1948; Hutchinson \& Robertson, 1966).

\section{MATERIALS AND METHODS}

Animals

A group of twenty Suffolk ewes aged 3 to 4 years, maintained indoors, was used. Oestrus was detected by running a vasectomized ram carrying a marking harness with each pen of ten ewes. The ewes were examined three times daily for service marks, the time of first marking being designated as the time of onset of oestrus and that day as Day 1 of the cycle.

\section{Surgical procedure}

Ewes were first anaesthetized by intravenous injection of pentobarbitone sodium $(30 \mathrm{mg} / \mathrm{kg}$ body weight). Laparotomy was then performed through a midline abdominal incision either for the purpose of marking the follicles present in the ovary or for removal of the ovaries. After completion of these procedures, the uterus was returned to the peritoneal cavity and the abdominal wall reconstituted in two layers using chromic catgut. Standard aseptic techniques were used throughout.

\section{Marking of Graafian follicles}

All large follicles ( 4 to $5 \mathrm{~mm}$ ) visible in the ovaries at the time of laparotomy were marked with carbon. Two microlitres of a sterile solution of Indian ink, previously dialysed extensively against physiological saline, was injected from a micrometer syringe fitted with a 27-gauge needle into the lumen of each large follicle, the needle entering through the tissue surrounding the basal part of the follicle. Using this technique, the needle track was occluded effectively by the tissue and little if any follicular fluid was lost. 


\section{Photographic record}

A Nikkon camera fitted with an electronic flash and close-up lens was used to take colour slides of the ovaries in situ and of sections of the fixed ovaries.

\section{Experimental procedures}

a. Preliminary experiments were carried out with three ewes to test the method of labelling follicles and to observe the subsequent development of large follicles marked on the 6 th or 7 th day of the oestrous cycle. In these animals, the fate of the labelled follicles was assessed visually at laparotomy on the 13th day of the cycle. However, the marked follicles were no longer clearly visible on the surface of the ovary and, in subsequent studies, the ovaries were fixed in phosphate-buffered formalin (Lillie, 1965) and sectioned with a scalpel to locate all marked follicles and/or corpora lutea present.

b. The fate of follicles marked during the 'inter-oestrus' period was studied in each of seven ewes subjected to three laparotomies over a period of approximately 16 days as shown in Table 1 . The first laparotomy was performed on the

TABLE 1

THE TIME OF LABELLING FOLLIGLES IN THE OVARIES OF SEVEN EWES RELATIVE TO THE TIME OF ONSET OF OESTRUS*

\begin{tabular}{c|c|c|c|c}
\hline Sheep no. & $\begin{array}{c}\text { Time of first } \\
\text { marking of } \\
\text { follicles } \\
\text { (days after } \\
\text { oestrus) }\end{array}$ & $\begin{array}{c}\text { Time of second } \\
\text { marking of } \\
\text { follicles } \\
\text { (days after } \\
\text { oestrus) }\end{array}$ & $\begin{array}{c}\text { 'Inter- } \\
\text { oestrus' } \\
\text { interval } \\
\text { (days) }\end{array}$ & $\begin{array}{c}\text { Time of } \\
\text { ovariectomy } \\
\text { (day of } \\
\text { second cycle) }\end{array}$ \\
\hline 315 & 6 & 13 & N.D. $\$$ & 4 \\
308 & 7 & 14 & 18 & 6 \\
305 & 7 & 13 & N.D. & 6 \\
322 & 7 & 14 & 17 & 9 \\
316 & 7 & 14 & 17 & 9 \\
311 & 9 & 15 & 18 & 4 \\
317 & 9 & 15 & 19 & 3 \\
\hline
\end{tabular}

* Follicles were marked with carbon twice during a single cycle, and the ovaries were removed for examination in the next cycle.

t Although the 'inter-oestrus' intervals are within the normal range for this flock, a slight prolongation of the cycle may have been caused in those ewes where pentobarbitone sodium was administered at a time close to the end of the cycle.

$\ddagger$ N.D. = Oestrus not detected.

6 th, 7th or 9th day after the onset of oestrus at which time all the large follicles visible in the ovaries were marked with carbon. Six or 7 days later in the same cycle all large, unmarked follicles present were marked in a similar manner. At an early stage in the next oestrous cycle (between the 3rd and 9th day), ovaries containing marked follicles were removed, fixed and sectioned.

c. To determine whether the ovarian follicles ovulated and subsequently formed a corpus luteum following injection of carbon, laparotomies were performed on two ewes (Nos. 310 and 309) 8 to $10 \mathrm{hr}$ after the time when oestrus was first detected by hourly observations of the animals. In each case, the one large follicle present was marked with carbon. Eleven days later the ovaries containing the marked follicles were removed, fixed and sectioned. 
To assess the activity of the corpus luteum before its removal and to determine whether ovulation occurred subsequently, daily blood samples were taken from the jugular vein of each ewe for 21 days from the time of the first detected oestrus and analysed for progesterone using a modification of the competitive protein-binding technique described by Neill, Johannson, Datta \& Knobil (1967).

d. In order to see how follicle growth was modified by the absence of a corpus luteum early in the oestrous cycle, a laparotomy was carried out on one ewe (No. 314) approximately $36 \mathrm{hr}$ after the onset of oestrus and a recently ruptured follicle present in the left ovary was destroyed by electrocautery. A second laparotomy was performed 18 days later and a large follicle present in the right ovary was marked. Oestrus was detected on the following day, and 7 days later the ovary containing the corpus luteum of the new cycle was removed, fixed and sectioned. Progesterone analyses were carried out on daily blood samples as described above.

e. The effect on follicular development of removal of the corpus luteum at mid-cycle was examined in the remaining ewe (No. 304). A single large follicle present in the left ovary on the 7th day of the cycle was marked, and the right ovary containing a corpus luteum was removed. Oestrus was detected 2 days later, and on the 7th day of the ensuing cycle the left ovary was removed for fixation and examination to see whether the marked follicle had ovulated and developed into a corpus luteum. This experiment, in which the source of progesterone was removed on the 7 th day of the cycle, enabled us to test the ovulatory capacity of a follicle which had enlarged to approximately $5 \mathrm{~mm}$ diameter during the early part of the oestrous cycle.

f. The size of follicles in anoestrous and pregnant ewes was examined by removing the ovaries from a series of non-lactating ewes in anoestrum and of ewes in late pregnancy. The ovaries were fixed, cut in 1-mm sections, and examined under a 1-mm grid to determine the diameter of the visible follicles.

\section{RESULTS}

Fate of follicles marked within the 'inter-oestrus' period

In six of the seven ewes in which follicles were marked with carbon early in the cycle (Table 1), the same pattern emerged. All of the follicles which had been marked between the 6th and 9th day of the cycle appeared to have regressed at the time of the second laparotomy. The new, large follicles which were marked at the second laparotomy also regressed, as shown by examination of sections of the ovary after it was removed during the second oestrous cycle. This examination confirmed that all the marked follicles had regressed and could be identified as sharply defined patches of carbon in the ovary, concentrated into small black vesicles. The corpora lutea were normal and contained no trace of carbon. Examples of these are shown in Plate 1.

In the remaining ewe (No. 322), the two large follicles marked on the 7th day of the cycle regressed, but two medium-large follicles marked on the 14th day did ovulate, developing into normal corpora lutea containing carbon in the centre (Plate 1). 
Fate of follicles marked during pre-ovulatory enlargement

When the large follicle present 8 to $10 \mathrm{hr}$ after the onset of oestrus, i.e. during the early stages of pre-ovulatory enlargement, was marked with carbon (Ewes Nos. 310 and 309), the corpus luteum present in the ovary after ovulation contained carbon in the centre (Plate 1). In one ovary, that of No. 310, two corpora lutea developed, a smaller one which was not marked apparently developing from a small follicle not visible at laparotomy. This result showed conclusively that the labelled follicles still retained the capacity to ovulate, become luteinized, and secrete progesterone. The progesterone levels in the peripheral plasma of these two ewes were normal for the oestrous cycle following the marking of the follicle (Text-fig. 1), suggesting that the presence of carbon in the corpus luteum had not impaired its endocrine function. It remains uncertain whether the presence of carbon in the follicle for a more prolonged period might damage the follicle, causing it to regress.
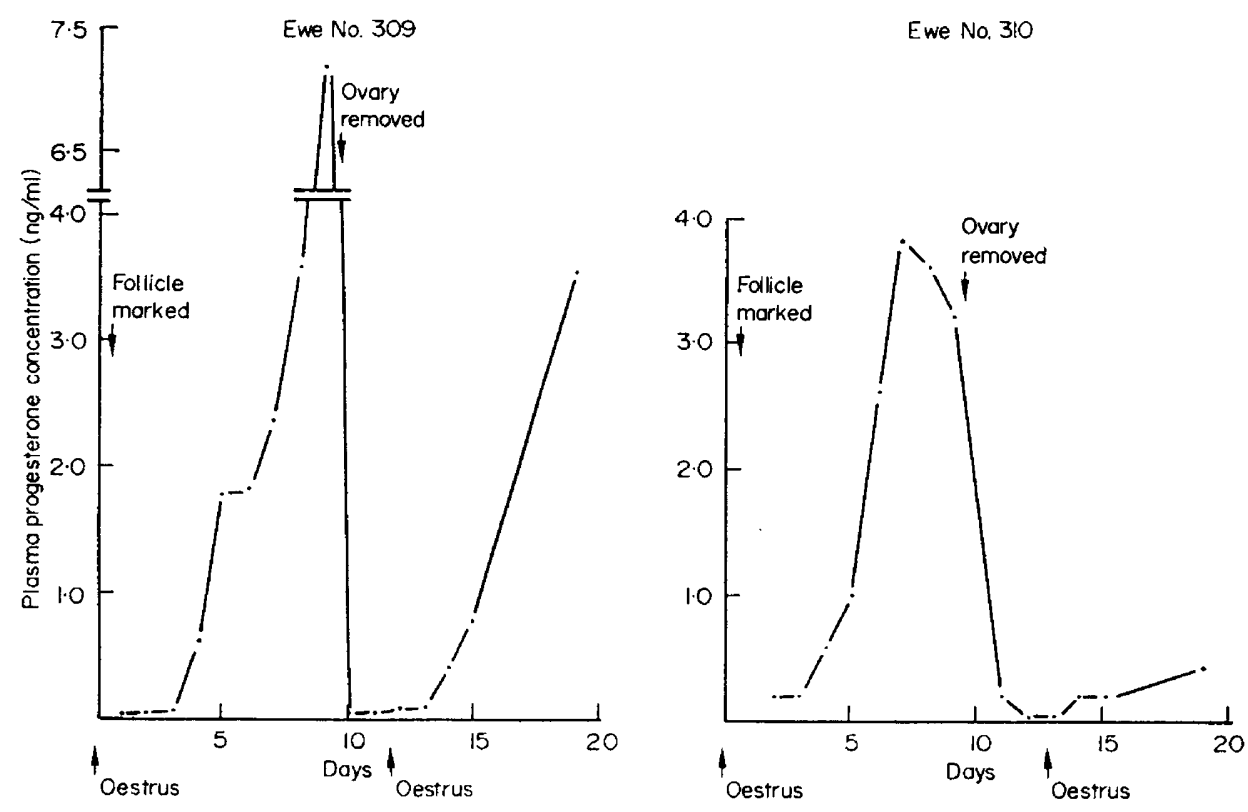

Texr-FIG. 1. Levels of progesterone in the peripheral plasma of two ewes following the marking of ovarian follicles during oestrus. The marked corpora lutea produced normal circulating levels of progesterone in both sheep. Note that the progesterone levels dropped sharply after removal of the corpus luteum and then rose after the ovulation which followed.

The effects of cauterization of a recently ruptured follicle

Cauterization of the recently ruptured follicle about $36 \mathrm{hr}$ after the onset of oestrus (Ewe No. 314) caused another ovulation to occur 48 to $72 \mathrm{hr}$ later, i.e. approximately 60 to $84 \mathrm{hr}$ after the previous ovulation. This was suggested by the progesterone levels in the plasma (Text-fig. 2), and was confirmed by examination of the ovary 18 days later when both a corpus luteum and a small cauterized area were visible at the surface of the ovary. There was no detectable 
oestrus, which would be expected if a recent preconditioning period with progesterone is required for oestrous behaviour (Robinson, 1954).

The large follicle which had been marked at the second laparotomy must have ovulated since the corpus luteum of the ensuing cycle contained carbon (Plate 1). In this case and in the one cited previously (Ewe No. 322), a large follicle present just before oestrus did ovulate, suggesting that normally only the follicles which enlarge during the 2 days before oestrus ovulate and form corpora lutea.

\section{The effects of removal of the corpus luteum at mid-cycle}

When the ovary containing the corpus luteum was removed at mid-cycle (Ewe No. 304), the ewe returned to oestrus 2 days later. This finding is in agreement with those of McKenzie \& Terrill (1937), Lang (1965) and Robertson (1969). The progesterone levels in the plasma confirmed that ovulation did occur, and a functional corpus luteum developed (Text-fig. 2). The levels of progesterone dropped sharply after removal of the corpus luteum, and began to rise about 3 days after ovulation, which is the normal pattern for an oestrous cycle (Thorburn, Bassett \& Smith, 1969).

The follicle which was marked at the time of removal of the corpus luteum on the 7th day of the cycle did not ovulate but regressed, as shown by the small patch of carbon found in the ovary after sectioning (Plate 1). Another follicle, which was not visible at laparotomy and which, due to the size of the marked follicle relative to the size of the ovary, was unlikely to exceed $2 \mathrm{~mm}$ in diameter, enlarged and ovulated. Ovarian follicles would, therefore, appear to have the capacity to grow rapidly from about $2 \mathrm{~mm}$ in diameter to a follicle ripe for ovulation within the space of 2 to 3 days.

\section{Follicle size in anoestrous and pregnant ewes}

The size and number of follicles present in the ovaries of anoestrous ewes and ewes in late pregnancy are shown in Table 2. It is obvious that there were no large follicles present in any of these ovaries, though large follicles were present during early gestation. It is reasonable to conclude that the cyclic pattern of growth and atresia of follicles seen in ewes during the breeding season

\section{EXPLANATION OF PLATE 1}

Sections of ovaries from ewes in which large Graafian follicles were marked with carbon at different times during the oestrous cycle.

Fig. 1. Ewe No. 315. Two marked, regressing follicles (arrows) are present, distinct from the newly formed corpus luteum (CL), and the degenerating corpus luteum (d) of the previous cycle.

Fig. 2. Ewe No. 305. Two marked, regressing follicles (arrows), a newly enlarged follicle (f) and the corpus luteum of the second cycle (CL) can be seen in the section.

Fig. 3. Ewe No. 322. Two healthy corpora lutea, both marked with carbon, are present in the section.

Fig. 4. Ewe No. 314. A small patch of carbon (arrow) can be seen in the centre of the recently formed corpus luteum, showing that the marked follicle became luteinized.

Fig. 5. Ewe No. 309. The corpus luteum, marked with carbon, developed from a follicle marked at 8 to $10 \mathrm{hr}$ after the onset of oestrus.

Fig. 6. Ewe No. 304. The regressing follicle (arrow) was marked on the 7 th day of the oestrous cycle at the same time as the other ovary containing the corpus luteum was removed. Another follicle ruptured and developed into the new corpus luteum seen in the section. 


\section{PLATE 1}
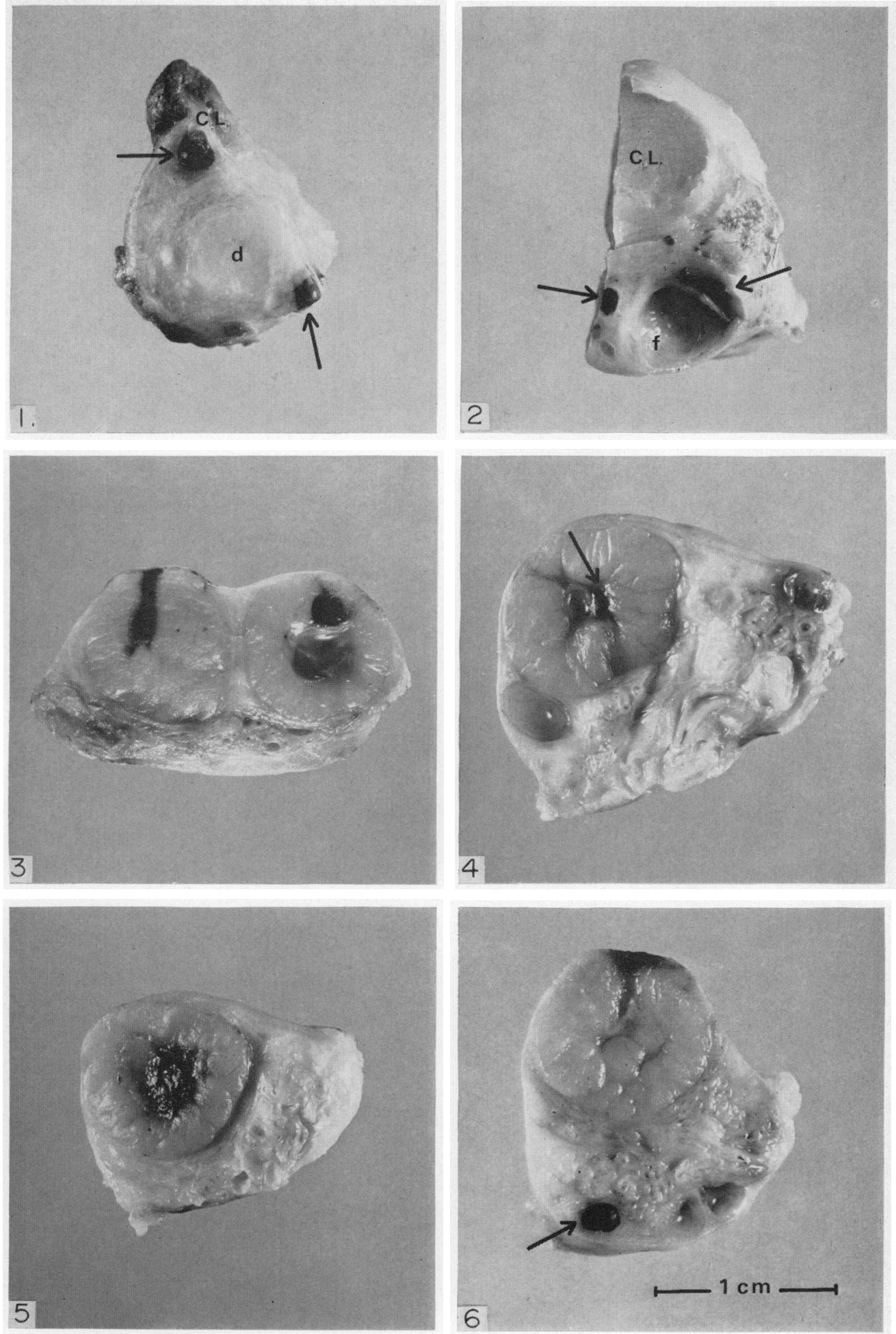

(Facing p. 248) 
was absent, or very much suppressed, during the anoestrous period or in the latter part of pregnancy. This is in agreement with the findings of Williams, Garrigus, Norton \& Nalbandov (1956), who showed that the mean follicle diameter decreased as pregnancy advanced.

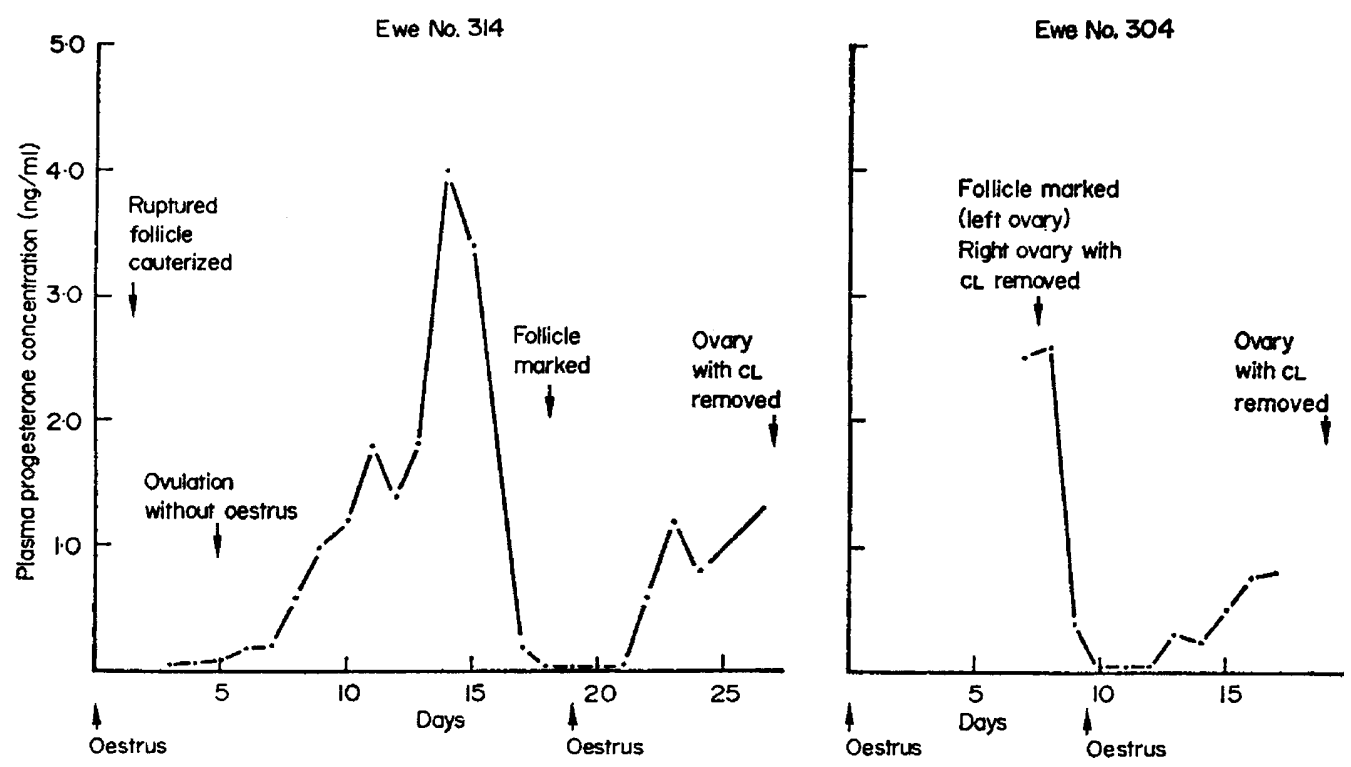

TExT-Fig. 2. The levels of progesterone in the peripheral plasma of two ewes following either the cauterization of a recently ruptured follicle $36 \mathrm{hr}$ after the onset of oestrus or the removal of the corpus luteum at mid-cycle. Large follicles present at laparotomy were marked with carbon at the times shown, and the ovaries which contained these follicles were removed subsequently.

TABLE 2

THE NUMBER AND SIZE OF VISIBLE FOLLIGLES IN THE OVARIES OF EWES DURING ANOESTRUM AND IN LATE PREGNANGY

\begin{tabular}{|c|c|c|c|c|c|c|}
\hline & \multicolumn{5}{|c|}{ Mean no. of follicles/ovary } & \multirow{3}{*}{$\begin{array}{l}\text { No. of } \\
\text { ewes }\end{array}$} \\
\hline & \multicolumn{5}{|c|}{ Follicle diameter $(\mathrm{mm})$} & \\
\hline & 1 & 2 & 3 & 4 & 5 & \\
\hline Anoestrous ewes & $7 \cdot 1 \pm 0.9$ & $8 \cdot 1 \pm 1 \cdot 2$ & $3 \cdot 1 \pm 0 \cdot 6$ & $0.5 \pm 0.2$ & $0 \cdot 25 \pm 0 \cdot 1$ & 8 \\
\hline $\begin{array}{l}105 \text { days } \\
125 \text { days } \\
140 \text { days }\end{array}$ & $\begin{array}{c}9.8 \pm 1.4 \\
7.0 \\
9.8\end{array}$ & $\begin{array}{c}5 \cdot 1 \pm 0 \cdot 8 \\
4 \cdot 5 \\
5 \cdot 1\end{array}$ & E & Z & $=$ & $\begin{array}{l}6 \\
1 \\
1\end{array}$ \\
\hline
\end{tabular}

* Two ovaries from each ewe were examined.

\section{DISCUSSION}

Attempts to increase productivity of domestic species such as the ewe and the cow by artificial means such as superovulation and synchronization of oestrus have met with limited success, perhaps due in part to a lack of knowledge of the factors which govern the normal growth and development of the Graafian 
follicle. If the time at which the developing follicle is receptive to stimulation and can be induced to ovulate could be established, then procedures for the induction of ovulation could continue on a more rational basis. With a view to finding out more of the normal pattern of growth of the follicle, the methods described in this paper were developed, and the experiments which have been carried out so far have been recorded above. In the interpretation of the results, we have assumed that the follicles marked with carbon behave in the same way as unlabelled follicles. Although this point has not been established beyond doubt, the appearance of the regressing marked follicles is similar, apart from the trapped carbon particles, to that of other atretic follicles. There is no evidence for luteinization or other abnormalities. Unfortunately, the nature of the system precludes the use of adequate controls, i.e. by injecting the follicles with saline, since alternative methods of labelling follicles externally or following the fate of unmarked follicles by sequential photography are not specific enough to identify a particular follicle several days later (Robertson, unpublished).

In the work described here, three different follicles have been shown to attain a diameter of $5 \mathrm{~mm}$ or more during the oestrous cycle of the ewe. One large follicle present early in the cycle (6th to 9th day) and another which had enlarged by the 13th to 15th day, regressed before the next oestrus. The follicle which finally ovulated grew rapidly to the $5-\mathrm{mm}$ size during the 36 to $48 \mathrm{hr}$ between the regression of the corpus luteum and the onset of oestrus. This follicle then underwent pre-ovulatory enlargement (up to about $12 \mathrm{~mm}$ ) during the period from onset of oestrus to ovulation. In the ewe, therefore, three waves of follicular growth have been detected and more may be present. It seems probable that the rapid increase in size of a follicle on the last day of the cycle and during oestrus is only one of a large number of growth cycles. When oestrus and ovulation occur, they are particular events superimposed on the cyclic growth of follicles, which is going on continually during the oestrous period. Only those follicles which are in a receptive state, i.e. increasing in size, at the time the corpus luteum starts to regress and the progesterone level to decline, will ovulate. If two follicles are both in the same phase of growth, then two ovulations can occur with one follicle sometimes substantially larger than the other, due presumably to its growth phase being slightly ahead of the other at the time when pre-ovulatory enlargement began.

A similar pattern of growth of Graafian follicles has been suggested for two other species. In the mouse, Peters \& Levy (1966) showed that there were large follicles in the ovary which grew rapidly after they were labelled with $\left[{ }^{3} \mathrm{H}\right]$ thymidine and then regressed without rupturing. Hill \& White (1933) demonstrated that the population of large follicles visible on the surface of the ovaries of female rabbits in constant oestrus changed continuously. In 7 to 10 days, new follicles had replaced the follicles present originally, as judged by comparison of photographs of the ovaries. Since, in this species, ovulation only occurs post coitum and mating was not permitted, follicle rupture and corpus luteum formation were not superimposed on the pattern of follicle renewal.

Among the large domestic animals, the observations of Rajakoski (1960) and Hancock (1962) in the cow have suggested that there might be more than one wave of follicular enlargement during the oestrous cycle. 
The reason that this pattern of follicular growth in the ewe was not elucidated previously appears to be that in most of the earlier studies, a series of observations at different stages of the cycle in different animals has given only a statistical average of the number of large follicles present. A static picture of follicular growth thus obtained does not appear to relate closely to the dynamic growth and atresia suggested by our results which were obtained by following the fate of individual follicles. If the growth of a number of follicles occurs with each one slightly out of phase with the other, then a series of discrete observations will give the apparently static picture already described.

The results from Ewe No. 304, in which the ovary containing the corpus luteum was removed on the 7th day of the cycle showed that the largest follicle in the remaining ovary was not the one which ovulated 3 days later. This suggests that the large follicle present on the 7 th day had begun to regress and was no longer able to respond to endogenous gonadotrophic stimulation caused by the drop in progesterone following removal of the corpus luteum.

Robertson (1969) suggested that, in the absence of luteal tissue following ovulation, the sheep may have essentially a 4-day oestrous cycle, i.e. a cycle analogous to that of the rat. In any one cycle, therefore, the sheep may have four waves of follicular growth, of which only the last one normally leads to ovulation.

The explanation for the mechanism controlling the waves of the follicular growth remains uncertain.

\section{AGKNOWLEDGMENT}

The technical assistance of Mr D. Ostapyk is gratefully acknowledged.

\section{REFERENCES}

Boling, J. L, Blandau, R. J., Soderwall, A. L. \& Young, W. G. (1941) Growth of the Graafian follicle and the time of ovulation in the albino rat. Anat. Rec. 79, 313.

Burger, J. F. (1952) Sex physiology of pigs. Onderstepoort 7. vet. Res. 25, Suppl. No. 2.

Gole, H. H. (1930) Growth of ovine and bovine ovarian follicles. Am. F. Anat. 46, 261.

DutT, R. H. \& GASIDA, L. E. (1948) Alteration of the estrual cycle in sheep by use of progesterone and its effect upon subsequent ovulation and fertility. Endocrinology, 43, 208.

Everetr, J. W. (1961) The mammalian female reproductive cycle and its controlling mechanisms. In: Sex and Internal Secretions, 3rd edn, Vol. 1, p. 497. Ed. W. G. Young. Williams \& Wilkins, Baltimore.

Grant, R. (1934) Studies on the physiology of reproduction in the ewe. Trans. R. Soc. Edinb. 58, 1.

Hammond, J. (1927) The physiology of reproduction in the cow. Cambridge University Press, London.

Hancock, J. L. (1962) The clinical features of the reproductive organs of pregnant and non-pregnant cattle. Vet. Rec. 74, 646.

Hill, M. \& White, W. E. (1933) The growth and regression of follicles in the oestrous rabbit. $\mathcal{F}$. Physiol., Lond. 80, 174.

Hisaw, F. L. (1947) Development of the Graafian follicle and ovulation. Physiol. Rev. 27, 95.

Hutchinson, J. S. M. \& Robertson, H. A. (1966) The growth of the follicle and corpus luteum in the ovary of the sheep. Res. vet. Sci. 7, 17.

Kammlade, W. G., Welch, J. A., Nalbandov, A. V. \& Norton, H. W. (1952) Pituitary activity of sheep in relation to the breeding season. F. Anim. Sci. 11, 646 .

LANG, D. R. (1965) Synchronization of the ovarian cycle of the ewe after surgical suppression of the corpus luteum. F. Reprod. Fert. 9, 113.

I.ILLIE, R. D. (1965) Histopathologic technic and practical histochemistry, 3rd edn, p. 38. McGraw-Hill, New York.

MaKenzie, F. F. \& Terrill, C. E. (1937) Estrus, ovulation and related phenomena in the ewe. Bull. Mo. agric. Exp. Stn, No. 264, 1. 
Myers, H. I., Young, W. G. \& Dempsey, E. W. (1936) Graafian follicle development throughout the reproductive cycle in the guinea-pig, with especial reference to changes during oestrus (sexual receptivity). Anat. Rec. 65, 381.

Neill, J. D., Johannson, E. D. B., Datta, J. K. \& Knobil, E. (1967) Relationship between the plasma levels of luteinizing hormone and progesterone during the normal menstrual cycle. 7 . clin. Endocr. Metab. 27, 1167.

Parlow, A. F., Anderson, L. L. \& Melampy, R. M. (1964) Pituitary follicle-stimulating hormone and luteinizing hormone concentration in relation to reproductive stages of the pig. Endocrinology, $75,365$.

Pedersen, T. (1970) Determination of follicle growth rate in the ovary of the immature mouse. $\mathcal{F}$. Reprod. Fert. 21, 81.

Peters, H. \& Levy, E. (1966) Cell dynamics of the ovarian cycle. F. Reprod. Fert. 11, 227.

RAJAKOSKI, E. (1960) The ovarian follicular system in sexually mature heifers with special reference to seasonal, cyclical, and left-right variations. Acta endocr., Copenh. Suppl. 52, 1.

Robertson, H. A. (1969) The endogenous control of estrus and ovulation in sheep, cattle, and swine, Vitams Horm. 27, 91.

Robertson, H. A. \& Hutchinson, J. S. M. (1962) The levels of Fsh and LH in the pituitary of the ewe in relation to follicular growth and ovulation. F. Endocr. 24, 143.

Robinson, G. E. \& Nalbandov, A. V. (1951) Gonadotrophic hormone potency of the pig pituitary during the estrous cycle. F. Anim. Sci. 10, 469.

Robrnson, T. J. (1954) The necessity for progesterone with estrogen for the induction of recurrent estrus in the ovariectomized ewe. Endocrinology, 55, 403.

Santolucito, J. A., Clegg, M. T. \& Cole, H. H. (1960) Pituitary gonadotrophins in the ewe at different stages of the estrous cycle. Endocrinology, 66, 273.

Thorburn, G. D., Bassett, J. M. \& Smith, I. D. (1969) Progesterone concentration in the peripheral plasma of sheep during the oestrous cycle. $\mathcal{F}$. Endocr. 45, 459.

Williams, S. M., Garrigus, U. S., Norton, H. W. \& Nalbandov, A. V. (1956) The occurrence of estrus in pregnant ewes. F. Anim. Sci. 15, 978.

Young, W. C. (1961) The mammalian ovary. In: Sex and Internal Secretions, 3rd edn, Vol. 1, p. 449. Ed. W. C. Young. Williams \& Wilkins, Baltimore. 